\title{
Ensuring Equity: Graduate Education as a Site of Strategic Intervention in Disciplinary Cultures
}

Aliya R. Hoff, PhD Student, School of Human Evolution and Social Change aliya.hoff@asu.edu

\section{Executive Summary}

Despite targeted recruitment efforts, Black, Indigenous, and People of Color (BIPOC) remain severely underrepresented in STEM graduate programs in the United States. As a result, the pool of scientists eligible to hold faculty positions remains overwhelmingly white. Increasing recruitment without addressing the underlying aspects of disciplinary cultures that reproduce systems of oppression is insufficient and short-sighted. Graduate programs socialize the next generation of scholars into disciplinary cultures by implicitly and explicitly communicating racialized and gendered ideas about what it means to be a good scientist. ${ }^{1}$ As a result, graduate education offers a critical opportunity to disrupt and transform science by interrogating disciplinary norms and values that guide decision-making, expanding definitions of scientific excellence, and providing scientists with holistic mentorship and varied forms of social support. Graduate programs must be intentionally retooled to support the persistence and well-being of BIPOC graduate students in the School of Earth and Space Exploration.

\section{Problem Statement}

While there have been recent gains in the representation of BIPOC students enrolled in STEM undergraduate programs, there is a steep drop-off in the racial and ethnic diversity of graduate students in the United States. ${ }^{2}$ In 2016 , only $13 \%$ of science and engineering doctorates were awarded to BIPOC scholars, substantially lower than the $31 \%$ required to reflect the broader US population. ${ }^{3}$ As a result of this bottleneck, the proportion of STEM faculty who are white increases with rank. ${ }^{4}$ The persistence of marked disparities in higher levels of academia has caused researchers to critique diversity efforts that focus solely on recruiting BIPOC students as insufficient and unsustainable because they fail to address the root causes of such disparities. ${ }^{5}$

\footnotetext{
${ }^{1}$ Levya \& Alley 2020

${ }^{2}$ Espinosa et al. 2019; Arizona State University is no exception to this trend. In fall 2019, minoritized students made up $44 \%$ of total undergraduate (immersion) enrollments but only $23 \%$ of graduate enrollments (Office of Institutional Analysis 2020). Diversity is even lower in the School of Earth and Space Exploration: in fall 2016, minoritized students made up $30 \%$ of undergraduate and $15 \%$ of doctoral enrollments (Arrowsmith et al. 2017).

${ }^{3}$ Bernard \& Cooperdock 2018; NSF 2018, 2019. Geosciences have the lowest proportion of doctorates earned by BIPOC scholars in STEM (6\%) and have not made significant gains in the past forty years.

${ }^{4}$ Espinosa et al. 2019

${ }^{5}$ Clancy et al. 2017; NASEM 2020; see also Slay \& Posselt 2019 on the diversity "bait and switch" move
} 
Enduring institutional change requires the transformation of entrenched disciplinary cultures that shape scientists' values, beliefs, and practices. ${ }^{6}$

As the principal location for the selection and training of the next generation of scientists, graduate education offers a critical site of intervention for equity work. ${ }^{7}$ During graduate school, students are socialized into particular disciplinary cultures as they develop their identity as a scientist and cultivate the knowledge and skills necessary to conduct research. ${ }^{8}$ However, to demonstrate mastery of their discipline, graduate students must also successfully navigate the "hidden curriculum"- the tacit norms and values that underlie expectations of how scientists should think and behave. ${ }^{9}$ As these norms and values become internalized and taken-for-granted, they become increasingly difficult to identify and challenge.

Thus, graduate education offers an ideal opportunity to analyze disciplinary norms and practices that systematically exclude certain groups of people and allow academia to remain a white, patriarchal space. ${ }^{10}$ It also offers a unique opportunity to enact long-lasting and widespread disciplinary change: strategically intervening in graduate student socialization by embedding equity work as a valuable and expected part of doing science can have considerable downstream effects as new PhDs move on to work and teach at other institutions. ${ }^{11}$ The following section discusses recommendations for interrogating implicit disciplinary norms, values, and beliefs so they can be intentionally retooled to promote the persistence and well-being of BIPOC graduate students.

\section{Recommendations}

The School of Earth and Space Exploration is already pursuing several recommended paths for increasing recruitment of BIPOC graduate students (e.g., robust public outreach, partnerships with Minority-Serving Institutions, and participating in PhD bridge programs). However, the unit must continue to address foundational norms, values, and beliefs that shape everyday scientific practices and social interactions if the ultimate goal is to achieve equity (see Figure 1). Equity goes beyond diversity and inclusion because it requires disrupting entrenched systems of power rather than assimilating people with diverse backgrounds into unchanged systems.

\section{Excavate and interrogate the foundational norms and values that guide decision-making in your department and discipline(s). For example, disciplinary cultures that value brilliance and overwork, promote the myth of}

\footnotetext{
${ }^{6}$ Posselt 2020; Posselt et al. 2017; Marín-Spiotta et al. 2020; Clancy et al. 2017

${ }^{7}$ Posselt 2020

${ }^{8}$ Austin 2002; Gardner 2006; Golde 2005; Gopaul 2011

${ }^{9}$ Margois \& Romero 1998

${ }^{10}$ See Levya \& Alley 2020 for a theorization of white, patriarchal spaces in education

${ }_{11}$ Posselt 2020; Posselt et al. 2017; Perez et al. 2019; see also NASEM 2018 for significance of graduate education to science in general
} 
meritocracy and performance of masculine stereotypes, and tolerate incivilities and confrontation tend to have fewer women in the field. ${ }^{12}$ Similar aspects of disciplinary culture may contribute to the underrepresentation of BIPOC scholars.

a. Educate graduate students about the social dimensions of science and its role in reproducing systems of oppression. Encourage students to take relevant coursework outside of SESE or, alternatively, co-design a course tailored for SESE students. Invite colleagues from the College of Global Futures, School of Life Sciences, School of Human Evolution and Social Change, and the School of Social Transformation to present in department colloquia, journal clubs, and faculty meetings.

b. Create opportunities for individual reflection and peer discussion to develop critical consciousness and racial literacy. ${ }^{13}$ Communities of practice help individuals reflect on their exposure to power and privilege and use this knowledge to engage in activism. Attend carefully to group composition to prevent graduate students from expending emotional labor to educate faculty. ${ }^{14}$

2. Expand and reimagine definitions/criteria of scientific potential, merit, and excellence with careful attention to how specific criteria may reproduce historical inequities in access to resources. Revise all departmental evaluative processes and reward structures to align with these definitions (e.g., graduate admissions, annual evaluations, comprehensive exams, allocation of funds and research positions, honors and awards). A study of an applied physics program that trained $10 \%$ of all Black physicists in the U.S. over the past decade found that formalizing expansive definitions of student potential and success in evaluation criteria was key to recruiting and retaining BIPOC scholars. ${ }^{15}$

a. Disrupt the hidden curriculum by explicitly defining program expectations and criteria for success. Create rubrics to standardize evaluation processes and iterate as needed. Regularly retrain and debrief faculty who serve on review committees to avoid drift. ${ }^{16}$

b. Collect and analyze demographic data to detect systematic bias in graduate admissions, awards and grants, allocation of TA/RA positions, outcome of comprehensive exams, time to degree, etc. ${ }^{17}$

3. Provide graduate students with holistic mentorship and manifold sources of social support. Science is an inherently social enterprise that requires holistic mentorship to develop competencies across different domains (e.g., technical,

\footnotetext{
${ }^{12}$ Rodrigues \& Clancy 2020 (in NASEM 2020); Marín-Spiotta et al. 2020; see also Harding 2015

${ }^{13}$ Friere 1970; Mosley et al. 2020

${ }^{14}$ Porter et al. 2018

${ }^{15}$ Posselt et al. 2017

${ }^{16}$ Rudolph \& Basri 2020; see Posselt 2016 for in-depth recommendations regarding graduate admissions and Lamont 2010 for evaluation processes in academia more generally.

${ }^{17}$ Rudolph \& Basri 2020
} 
professional, cultural, etc.). Quality of mentorship is one of the most important factors in graduate student well-being and degree completion, while peer support is instrumental for retention and successfully navigating the hidden curriculum. ${ }^{18}$

a. Provide mentorship training for all members of the department. Instead of reproducing inherited modes of mentorship that serve particular people, mentors must be prepared to provide individualized support to students with diverse backgrounds, perspectives, and experiences. Continue encouraging students to cultivate multiple mentors within and beyond SESE and extend existing peer mentoring programs. Require faculty to draft explicit mentorship compacts with their mentees and submit an annual reflection/evaluation of their mentorship style and its efficacy.

b. Promote safe and supportive working environments. Continue offering workshops to develop sociocultural competencies necessary for collaborative research (e.g., bystander intervention, microaggressions, sexual misconduct, universal design, culturally responsive pedagogy). ${ }^{19}$ Draft policies that explicitly define expected norms of conduct, reporting mechanisms, and accountability measures for SESE members.

Encourage faculty to tailor these policies for their research groups and field sites. Policies must align with disciplinary values to avoid becoming yet another bureaucratic checkbox. ${ }^{20}$

4. Collaborate with social scientists to identify areas in need of attention and to evaluate the perceived efficacy of specific interventions. Semi-structured interviews provide nuanced understandings of lived experience, while focus groups provide insight into shared beliefs and perceptions. Ethnographic research is ideal for surfacing cultural norms and values via the observation of everyday practices and interactions. Social scientists are trained to minimize risk to participants and protect confidentiality.

Without targeted and intentional interventions to change disciplinary cultures, other diversity and inclusion efforts are unlikely to be successful or durable. Interrogating and challenging taken-for-granted assumptions and engrained patterns of behavior requires a sustained commitment to the growth of ourselves and our communities. Cultural change is neither quick nor comfortable, but it is a prerequisite for transforming systems of oppression in service of equity. Graduate education is a critical site of intervention where science can be reimagined as a more expansive, equitable, and supportive enterprise that benefits all scientists and serves as a corrective for historical and ongoing injustices.

\footnotetext{
${ }^{18}$ NASEM 2018, 2019, 2020

${ }^{19}$ Marín-Spiotta et al. 2020; Rudolph \& Basri 2020

${ }^{20}$ Ahmed 2012
} 
How do disciplinary cultures affect the retention of

Black, Indigenous, and People of Color (BIPOC)

pursuing graduate degrees in STEM?

Scientists who are underrepresented in their discipline, including BIPOC scholars, innovate at greater rates than scientists from dominant groups but are less likely to secure a successful career in science (1).
Many people call the lack of diversity in STEM a "leaky pipeline" problem and focus on trying to fill the pipeline by recruiting BIPOC students...

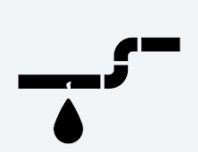

but the road to becoming a scientist is more like running a gauntlet where certain people receive more blows than others (2).

\section{Diversity efforts to increase recruitment of BIPOC students are} incomplete, unsustainable, and potentially harmful without concomitant changes in disciplinary culture (3).

Increasing recruitment without addressing the underlying causes of historical disparities is like lining up more people to run the gauntlet without reducing the blows they receive.
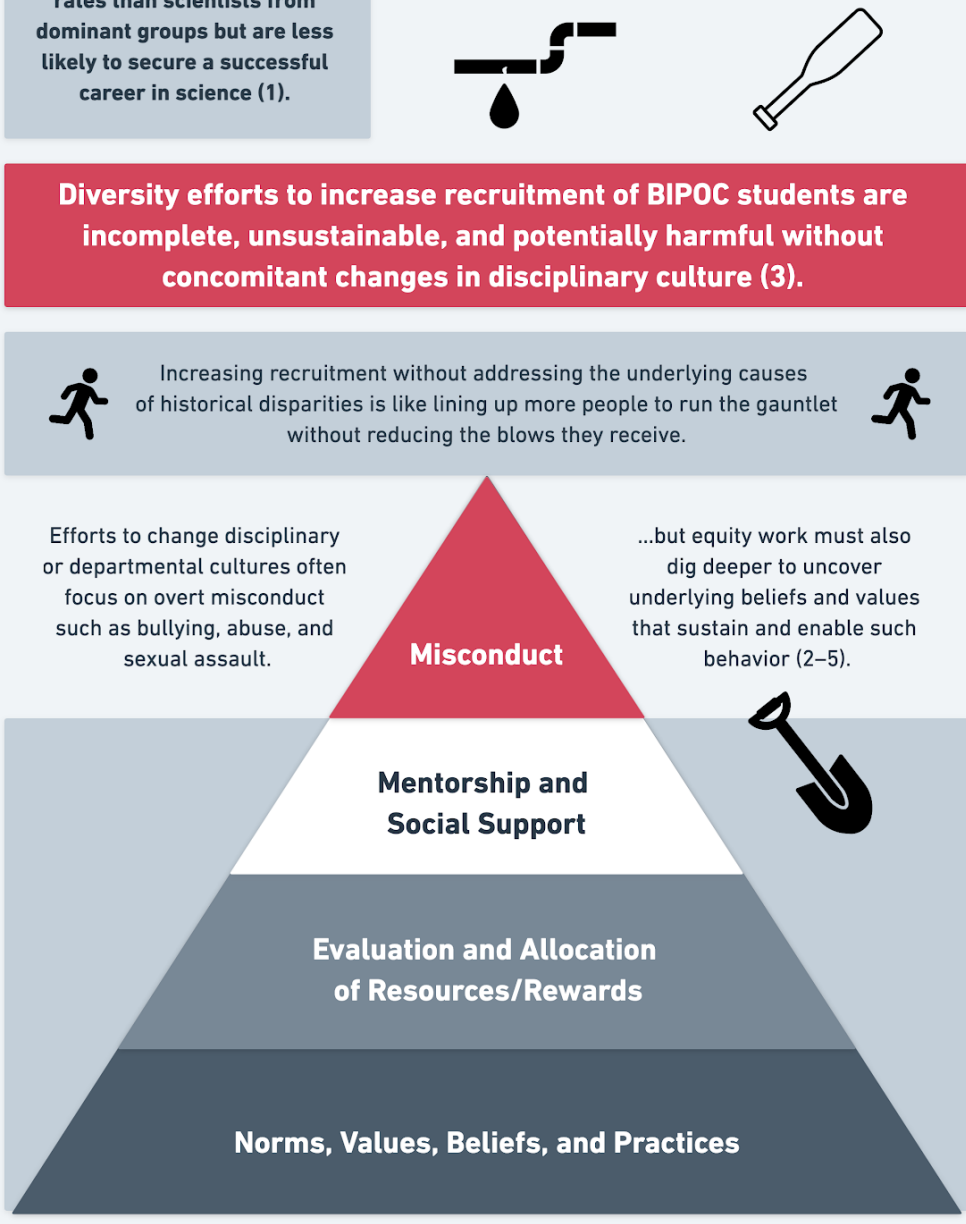

Transforming Disciplinary Cultures

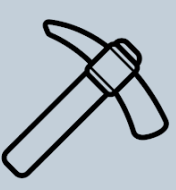

Excavate and interrogate foundational assumptions about doing science

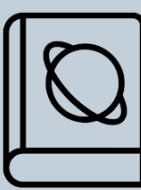

Expand the definition of what counts as science and who makes a good scientist

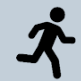




\section{Recommended Reading}

Posselt, Julie R. 2020. Equity in Science: Representation, Culture, and the Dynamics of Change in Graduate Education. Stanford: Stanford University Press.

Posselt's book is a must-read for those interested in graduate education. The first chapter explains why graduate education is a key site for equity work, while the final chapter provides a useful synthesis and recommendations. The case-studies are also worth reading: they detail successful and unsuccessful aspects of JEDI efforts in physics, astronomy, and the geosciences.

National Academies of Sciences, Engineering, and Medicine. 2020. Promising Practices for Addressing the Underrepresentation of Women in Science, Engineering, and Medicine: Opening Doors. Washington, DC: The National Academies Press.

This consensus report provides a comprehensive literature review and evidence-based recommendations. The commissioned paper by Michelle A. Rodrigues and Kathryn B.H. Clancy is an excellent resource that explores how specific disciplinary cultures, practices, and histories result in various degrees of severity of women's underrepresentation across STEM.

National Academies of Sciences, Engineering, and Medicine. 2019. The Science of Effective Mentorship in STEMM. Washington, DC: The National Academies Press. A must-read NASEM report for anyone with mentoring responsibilities. The commissioned papers provide in-depth reviews of different approaches to mentoring, while the companion website provides easy access to recommendations and tools.

Marín-Spiotta, Erika, et al. 2020. "Hostile Climates Are Barriers to Diversifying the Geosciences." Advances in Geosciences 53: 117-27.

Succinct and powerful description of the dismal state of diversity in the geosciences that directs attention to historical legacies of exclusion, power dynamics, and aspects of disciplinary culture that reproduce inequities.

Clancy, Kathryn B. H., et al. 2017. "Double jeopardy in astronomy and planetary science: Women of color face greater risks of gendered and racial harassment." Journal of Geophysical Research: Planets 122(7): 1610-23.

Reports shockingly high instances of negative workplace experiences in the earth and space sciences and highlights the "double jeopardy" that women of color face due to the intersection of racism and sexism.

Posselt, Julie R. 2016. Inside Graduate Admissions: Merit, Diversity, and Faculty Gatekeeping. Cambridge, MA: Harvard University Press. 
Posselt demonstrates how tacit assumptions of what constitutes excellence, merit, and potential in science open the door for implicit bias in graduate admissions and other processes of evaluation.

Ahmed, Sara. 2012. On Being Included: Racism and Diversity in Institutional Life. Durham, NC: Duke University Press. Ahmed interviews diversity workers in the U.K. While the organization of higher education and policy landscape is different, this book is helpful for anticipating common ways that JEDI work "gets stuck" or comes up against institutional walls.

\section{Works Cited}

Austin, Ann E. 2002. "Preparing the next generation of faculty: Graduate school as socialization to the academic career." Journal of Higher Education 73(1): 94-122.

Arrowsmith, Ramon, Amanda Clarke, Evan Scannapieco, Phil Mauskopf, and Linda Elkins-Tanton. 2017. Academic Program Review Self-Study Report (2010-2017) for the School of Earth and Space Exploration (SESE). Arizona State University.

Clancy, Kathryn B. H., Katharine M. N. Lee, Erica M. Rodgers, and Christina Richey. 2017. "Double jeopardy in astronomy and planetary science: Women of color face greater risks of gendered and racial harassment." Journal of Geophysical Research: Planets 122(7): 1610-23.

Espinosa, Lorelle L., Jonathan M. Turk, Morgan Taylor, and Hollie M. Chessman. 2019. Race and Ethnicity in Higher Education: A Status Report. American Council on Education.

Friere, Paulo. 1970. Pedagogy of the Oppressed. New York: Continuum Press.

Gardner, Susan K. 2006. "I heard it through the grapevine: Doctoral student socialization in chemistry and history." Higher Education 54(5): 723-740.

Golde, Chris M. 2005. "The role of the department and discipline in doctoral student attrition: Lessons from four departments." Journal of Higher Education 76(6): 669-700.

Gopaul, Bryan. 2011. "Distinction in doctoral education: Using Bourdieu's tools to assess the socialization of doctoral students." Equity \& Excellence in Education 44(1): $10-21$. 
Harding, Sandra. 2015. Objectivity and diversity: Another logic of scientific research. Chicago: Chicago University Press.

Leyva, Luis A., and Zander D. Alley. 2020. "A counter-storytelling of struggle and support in Black women's mathematical talent development and STEM pursuits across white, patriarchal spaces in education." In Understanding the Intersections of Race, Gender, and Gifted Education: An Anthology by and About Talented Black Girls and Women in Stem, 85-106. Charlotte, NC: Information Age Publishing.

Margolis, Eric, and Mary Romero. 1998. "The department is very male, very white, very old, and very conservative: the functioning of the hidden curriculum in graduate sociology departments." Harvard Educational Review 68(1): 1-33.

Lamont, Michèle. 2010. How Professors Think: Inside the Curious World of Academic Judgment. Cambridge, MA: Harvard University Press.

Marín-Spiotta, Erika, Rebecca T. Barnes, Asmeret Asefaw Berhe, Meredith G. Hastings, Allison Mattheis, Blair Schneider, and Billy M. Williams. 2020. "Hostile Climates Are Barriers to Diversifying the Geosciences." Advances in Geosciences 53: 117-27.

Moseley, Della V., Candice N. Hargons, Carolyn Meiller, Blanka Angyal, Paris Wheeler, Candice Davis, and Danelle Stevens-Watkins. 2020. "Critical Consciousness of Anti-Black Racism: A Practical Model to Prevent and Resist Racial Trauma." Journal of Counseling Psychology.

National Academies of Sciences, Engineering, and Medicine. 2018. Graduate STEM education for the 21st century. Washington, DC: The National Academies Press.

National Academies of Sciences, Engineering, and Medicine. 2019. The Science of Effective Mentorship in STEMM. Washington, DC: The National Academies Press.

National Academies of Sciences, Engineering, and Medicine. 2020. Promising Practices for Addressing the Underrepresentation of Women in Science, Engineering, and Medicine: Opening Doors. Washington, DC: The National Academies Press.

National Science Foundation. 2018. 2016 Doctoral Recipients from U.S. Universities. National Center for Science and Engineering Statistics. https://ncses.nsf.gov/pubs/nsf21308 
National Science Foundation. 2019. Women, Minorities, and Persons with Disabilities in Science and Engineering. National Center for Science and Engineering Statistics. https://ncses.nsf.gov/pubs/nsf19304/

Office of Institutional Advancement. 2020. A Ten-Year Review of Students, Faculty, and Staff 2009-2019. Arizona State University.

Perez, Rosemary J., Claire K. Robbins, L. Wesley Harris, Jr., and Cheryl Montgomery. 2019. "Exploring graduate students' socialization to equity, diversity, and inclusion." Journal of Diversity in Higher Education 12(3).

Porter, Kamaria B., Julie R. Posselt, Kimberly A. Reyes, Kelly E. Slay, Aurora Kamimura. 2018. "Burdens and benefits of diversity work: Emotion management in STEM doctoral students." Studies in Graduate and Postdoctoral Education 9(2): 127-143.

Posselt, Julie R. 2016. Inside Graduate Admissions: Merit, Diversity, and Faculty Gatekeeping. Cambridge, MA: Harvard University Press.

Posselt, Julie R. 2020. Equity in Science: Representation, Culture, and the Dynamics of Change in Graduate Education. Stanford: Stanford University Press.

Posselt, Julie R., Kimberly A. Reyes, Kelly E. Slay, Aurora Kamimura, and Kamaria B. Porter. 2017. "Equity Efforts as Boundary Work: How Symbolic and Social Boundaries Shape Access and Inclusion in Graduate Education." Teachers College Record 119: $1-38$

Ray, Victor E. 2018. "A theory of racialized organizations." American Sociological Review 84(1): 26-53.

Rudolph, Alexander, and Gibor Basri. 2020. Final Report of the 2018 AAS Task Force on Diversity and Inclusion in Astronomy Graduate Education. American Astronomical Society. https://baas.aas.org/pub/2019i0101/release/1

Slay, Kelly E., Kimberly A. Reyes, and Julie R. Posselt. 2019. "Bait and switch? Representation, climate, and the tensions of diversity in graduate education." Review of Higher Education 42(5): 255-286. 